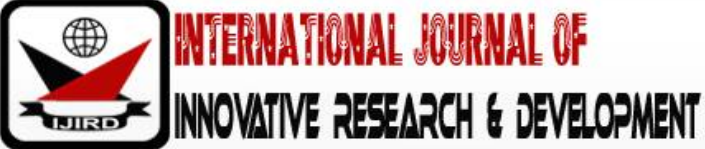

ISSN 2278 - 0211 (Online)

\section{Antifungal Activities of Alcaligenes Faecalis Palm Wine Isolate in Mice Model Vaginal Candidiasis}

Ikele, M.O
Lecturer, Department of Applied Microbiology and Brewing,
Nnamdi Azikiwe University, Nigeria
Ilikannu, S
Obasi, C.J.
Medical Officer, Federal Medical Center, Asaba, Nigeria
Lecturer, Department of Applied Microbiology and Brewing,
Nnamdi Azikiwe University, Nigeria
Okeke, B.C.
Lecturer, Department of Applied Microbiology and Brewing,
Nnamdi Azikiwe University, Nigeria
Ikele, B.C.
Lecturer, Department of Zoology and Environmental Biology,
University of Nigeria Nsukka, Nigeria
Nwakoby, N.E.
Technologist, Department of Microbiology,
Chukwuemeka Odumegwu Ojukwu University, Nigeria
Ukoha, C.C.
Lecturer, Department of Microbiology,
Chukwuemeka Odumegwu Ojukwu University, Nigeria
Victor-Aduloju, A.T.
Lecturer, Department of Food Science and Technology,
Nnamdi Azikiwe University, Nigeria
Aduloju, T.
Technologist, Department of Dental Technology, Federal College of Dental,
Technology and Therapy, Enugu, Nigeria
(a)

\begin{abstract}
:
Alcaligenes faecalis is a food borne transient microbe which has been reported to possess some antifungal properties. A. faecalis was assessed in vivo for use as a vaginal antifungal agent for the control of vaginal candidiasis. Fifty, three weeks old mice were used for the in vivo tests. Groups A and B were healthy and infected without treatment groups respectively. A $20 \mu \mathrm{l}$ aliquot of $12.8 \times 10^{6} \mathrm{cfu} / \mathrm{ml}$ of C. albicans was used to elicit vaginal infections. Suppository clotrimazole was used as antifungal agent to control the infection in Group C mice, while a $20 \mu \mathrm{l}$ aliquot of $10.8 \times 10^{8} \mathrm{cfu} / \mathrm{ml}$ of A. faecalis was infused into Groups D and E test mice and were used for treatment and prophylaxis of the infection respectively. Candidal counts, immunomodulatory roles of A. faecalis and vaginal histology were monitored through the experimental periods. There was a significant decrease $(\mathrm{p} \leq 0.05)$ in the candidal counts for groups $C, D$ and $E$ test mice. There was also significant increase $(\mathrm{p} \leq 0.05)$ in the white blood cell, lymphocyte and neutrophil counts of these same mice groups. Histopathology examination showed that A. faecalis could restore and also maintain normal vaginal architecture in Groups D and E respectively. These research findings show that A. faecalis possesses antifungal and immunomodulatory potentials for the control of vaginal cadidiasis infection.
\end{abstract}

Keywords: Antifungal, Alcaligenes, candidiasis, mice histology

\section{Introduction}

Alcaligenes faecalis is a Gram negative, obligate aerobic rod which primarily inhabits the alimentary canal where it lives as a commensal (Kahveci et al. 2011). It is oxidase positive, catalase positive, citrate positive and has flat, glistening, milky-white colonies with rhizoidal margin on culture plates. It has an apple to strawberry flavor on culture plates, survives at optimum temperature range of $35-37^{\circ} \mathrm{C}$ and at $\mathrm{pH}$ range of 4.8-9.0 (Santos et al. 2011). It could also be seen in 
soil, water, garri, palmwine, green olives, unpasteurized whole milk, raw fish and aquatic foods or any other food product that is unhygienically prepared. It is a non-pathogenic food contaminant which possesses some kind of bio-degrading and anti-microbial qualities such as; production of proteases, nitrous oxide, lipases, penicillin-G acyclase, bio-surfactants and bio-films. Its bio-degrading properties contribute to its ability to involve in food spoilage, enhancement of plant growth and treatment of waste waters. According to Daraei et al. (2009) and Santos et al. (2011), the organism has demonstrated antifungal activities against Aspergillus niger and Candida albicansin vitro.

Fungal vaginosis or mycotic vaginosis is mainly caused by the genus Candida, thus, it has been known with the name candidiasis. It is caused as a result of Candida overgrowth in the vagina due to an imbalance in the vagina microbial ecosystem. It is characterized by the production of white discharge which looks like cottage cheese from the vagina (Borchert et al. 2008). The species involved are Candida albicans and Candida glabrata, with Candida albicans being the most common pathogen.

Probiotics are microbes that confer certain health benefits to the host when consumed in adequate quantities (Gibson \& Fuller, 2000).The use of Alcaligenes faecalis as a probiotic source has been demonstrated in the class aves and pisces of the phylum Chordata. This has been demonstrated by (Phytopharma, 2006) and (Jaafar et al. 2011). Jaafar et al. (2011) demonstrated the use of this above mentioned microorganism in the treatment of fish skin disorder via incorporating it in fish feed as a dietary supplement while Phytopharma incorporated this microorganism in poultry feed as bio-amino acid, where it serves as electrolyte balance enhancer. Jaafar et al. (2011), postulated that it has a great advantage in aquaculture because the exopolysaccharides it produces act as immunostimulant against diseases.

\section{Materials and Methods}

\subsection{Molecular Identification of Alcaligenes faecalis}

This was done by The Mill Incorporate, Missouri, United States of America. The strain was struck to Trpticase Soy Agar and incubated under anaerobic conditions at $37^{\circ} \mathrm{C}$. The strain was processed using $16 \mathrm{~S}$ rRNA sequencing for identification.

\subsection{Mice Groups}

Five groups of ten mice each ( 3 weeks old) were used as stated below:

- Group A: Uninfected group (healthy control).

- Group B: Infected without treatment.

- Group C: Infected and treated with suppository Clotrimazole.

- Group D: Infected and treated with Alcaligenes faecalis isolate.

- Group E: First infused with Alcaligenes faecalis before infection with Candida albicans.

\subsection{Inoculation of Test Microorganisms}

Groups B, C and D were initially infused intra-vaginally with $20 \mathrm{\mu l}$ of 12.8 x $10^{6} \mathrm{cfu} / \mathrm{ml}$ of Candida albicans mixed with phosphate buffer saline with the aid of a microlitre pipette and left for a period of four days to give room for disease establishment. Afterwards, group D was infused intra-vaginally with $20 \mathrm{\mu l}$ of $10.8 \times 10^{8} \mathrm{cfu} / \mathrm{ml}$ of Alcaligenes faecalis also suspended in phosphate buffer saline, in order to initiate competitive inhibition. Group C was treated with suppository Clotrimazole while group B was left without treatment as stated above.

Group E was initially infused intravaginally with $20 \mu \mathrm{l}$ of $10.8 \times 10^{8} \mathrm{cfu} / \mathrm{ml}$ of Alcaligenes faecalis isolated from Palm wine and left for 4 days before infusing $20 \mu \mathrm{l}$ of $12.8 \times 10^{6} \mathrm{cfu} / \mathrm{ml}$ of Candida albicans. This group was used to ascertain the prophylactic ability of the Palm wine isolate on vaginal candidiasis (Pascual et al. 2009).

\subsection{Microbial Enumeration}

Vaginal lavage was performed on dead mice from each group with $100 \mu \mathrm{l}$ of phosphate buffer saline; lavage fluid was serially diluted and plated on Saboraud's Dextrose Agar. Colony forming units from lavage cultures after 24 hours were used to determine the vaginal Candida burden. This helped to reveal the position of Alcaligenes faecalis in prophylaxis and treatment of the disease and also helped to reveal the level of curative effect between Alcaligenes faecalis and Clotrimazole (Pascual et al. 2009).

\subsection{Haematological Analysis}

Packed cell volume, total white blood cell count and differential counts were performed to observe the leucocyte roles in the research, using their standard laboratory procedures, with blood samples taken from the medial canthus of the retro-bulbar plexus.

\subsection{Histopathological Examination}

This was done in order to have a detailed idea on the position of the antifungal activity of Alcaligenes faecalis on vaginal candidiasis. Vagina samples from each mice group were excised and immediately fixed in $10 \%$ neutral buffered formalin. The tissues were observed using their standard laboratory protocols. 


\section{Results}

\subsection{Effects of A. faecalis Administration on Vaginal Candida Load}

Vaginal Candida load of the test mice showed a significant $(P \leq 0.05)$ decrease in groups $C$ and $D$ which are the clotrimazole treated and A. faecalis treated groups respectively. Group E (A. faecalis prophylactic group) had similar range of Candida counts as the healthy control (Group A). While group B (infected without treatment) showed a continuous increase in Candida load and eventual decrease in the course of the infection as shown in Figure 1.

\subsection{Immunomodulatory Roles of A. faecalis on Vaginal Candidiasis Infection}

Immunomodulatory role shows that the test mice were not anaemic save for group B. A. faecalis elicited white blood cell activities mainly that of neutrophils and lymphocytes. There was no significant $(P \geq 0.05)$ difference in the immunomodulatory roles elicited by A. faecalis and clotrimazole treatment. Basophils, monocytes and eosinophils played no significant role in the infection control for all the test mice groups (tables 1-7).

\subsection{Effects of A. faecalis Administration on the Vaginal Histology of Test Mice}

Histopathological examination of the vaginal tissues showed distorted architecture for group B, and some recovered parts of the vaginal wall architecture for groups $C$ and D. However, group E showed intact vaginal wall architecture similar with group A (healthy control) as shown in plates 1-5.

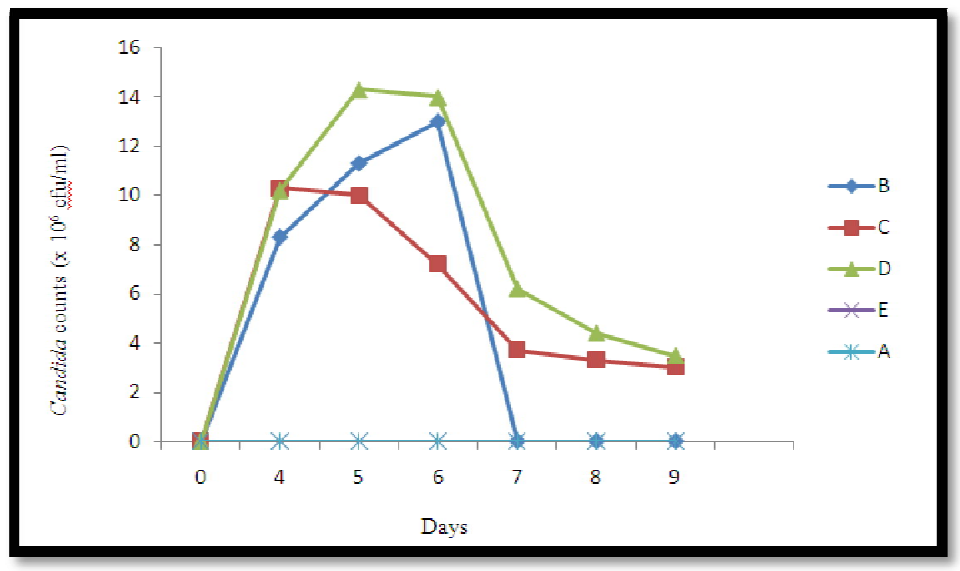

A: uninfected

Figure 1: Mean Candida load of Test Mice Vagina

B: infected without treatment

C: infected and treated with clotrimazole

D: infected and treated with A. faecalis

E: prophylactic group

\begin{tabular}{|c|c|c|}
\hline Treatment Groups & Mean \pm S.E(initial) & Mean \pm S.E (final) \\
\hline A & $33.00 \pm 2.52^{\mathrm{a}}$ & $33.67 \pm .67^{\mathrm{a}}$ \\
\hline B & $32.67 \pm .67^{\mathrm{a}}$ & $14.67 \pm 2.33^{\mathrm{c}}$ \\
\hline C & $33.00 \pm 2.52^{\mathrm{a}}$ & $26.33 \pm 2.40^{\mathrm{b}}$ \\
\hline D & $31.67 \pm .88^{\mathrm{a}}$ & $21.00 \pm 2.31^{\mathrm{b}}$ \\
\hline E & $30.67 \pm .33^{\mathrm{a}}$ & $37.00 \pm 2.65^{\mathrm{a}}$ \\
\hline
\end{tabular}

Table 1: Packed Cell Volume Values amongst Test Groups

Mean within the Same Column Followed by Different Suffixes Are Significantly Different ( $\mathrm{P} \leq 0.05)$

A: uninfected

B: infected without treatment

C: infected and treated with clotrimazole

D: infected and treated with A. faecalis

E: prophylactic group

\begin{tabular}{|c|c|c|}
\hline Treatment groups & Mean \pm S.E(initial) & Mean \pm S.E (final) \\
\hline A & $30.57 \pm 13.62^{\mathrm{b}}$ & $72.50 \pm 31.17^{\mathrm{ab}}$ \\
\hline B & $28.83 \pm 10.90^{\mathrm{ab}}$ & $38.83 \pm 10.10^{\mathrm{a}}$ \\
\hline C & $30.50 \pm 11.79^{\mathrm{b}}$ & $104.26 \pm 8.22^{\mathrm{b}}$ \\
\hline $\mathrm{D}$ & $29.77 \pm 35.55^{\mathrm{ab}}$ & $79.90 \pm 14.69^{\mathrm{ab}}$ \\
\hline $\mathrm{E}$ & $22.23 \pm 34.51^{\mathrm{a}}$ & $69.57 \pm 14 . .49^{\mathrm{ab}}$ \\
\hline
\end{tabular}

Table 2: Total White Blood cell Count Values amongst Test Groups

Mean within the Same Column Followed by Different Suffixes Are Significantly Different $(\mathrm{P} \leq 0.05)$ 
A: uninfected

B: infected without treatment

C: infected and treated with clotrimazole

D: infected and treated with A. faecalis

E: prophylactic group

\begin{tabular}{|c|c|c|}
\hline $\begin{array}{c}\text { Treatment } \\
\text { groups }\end{array}$ & Mean \pm S.E(initial) & Mean \pm S.E (final) \\
\hline A & $26.00 \pm 3.01^{\mathrm{a}}$ & $26.67 \pm 1.45^{\mathrm{b}}$ \\
\hline $\mathrm{B}$ & $33.67 \pm 3.28^{\mathrm{a}}$ & $9.00 \pm 1.15^{\mathrm{a}}$ \\
\hline $\mathrm{C}$ & $27.33 \pm 1.76^{\mathrm{a}}$ & $25.33 \pm 2.96^{\mathrm{b}}$ \\
\hline $\mathrm{D}$ & $26.00 \pm 3.21^{\mathrm{a}}$ & $24.33 \pm 2.67^{\mathrm{b}}$ \\
\hline $\mathrm{E}$ & $26.00 \pm 4.16^{\mathrm{a}}$ & $22.67 \pm 2.96^{\mathrm{b}}$ \\
\hline
\end{tabular}

Table 3: Neutrophil Values amongst Test Groups

Mean within the Same Column Followed by Different Suffixes Are Significantly Different ( $\mathrm{P} \leq 0.05)$

A: uninfected

B: infected without treatment

C: infected and treated with clotrimazole

D: infected and treated with A. faecalis

E: prophylactic group

\begin{tabular}{|c|c|c|}
\hline Treatment Groups & Mean \pm S.E(initial) & Mean \pm S.E (final) \\
\hline A & $54.67 \pm 2.45^{\mathrm{a}}$ & $73.33 \pm 2.96^{\mathrm{b}}$ \\
\hline B & $64.67 \pm 2.40^{\mathrm{a}}$ & $47.67 \pm 6.57^{\mathrm{a}}$ \\
\hline C & $68.00 \pm 2.00^{\mathrm{a}}$ & $70.67 \pm 1.33^{\mathrm{b}}$ \\
\hline D & $71.67 \pm 3.29^{\mathrm{a}}$ & $71.00 \pm 0.00^{\mathrm{b}}$ \\
\hline E & $70.00 \pm 4.61^{\mathrm{a}}$ & $63.67 \pm 4.81^{\mathrm{b}}$ \\
\hline
\end{tabular}

Table 4: Lymphocyte Values amongst Test Groups

Mean within the Same Column Followed By Different Suffixes Are Significantly Different ( $\mathrm{P} \leq 0.05)$

A: uninfected

B: infected without treatment

C: infected and treated with clotrimazole

D: infected and treated with A. faecalis

E: prophylactic group

\begin{tabular}{|c|c|c|}
\hline Treatment Groups & Mean \pm S.E(initial) & Mean \pm S.E (final) \\
\hline A & $1.00 \pm .58^{\mathrm{a}}$ & $2.00 \pm 1.00^{\mathrm{a}}$ \\
\hline B & $1.33 \pm .67^{\mathrm{a}}$ & $0.67 \pm .33^{\mathrm{a}}$ \\
\hline C & $1.00 \pm .65^{\mathrm{a}}$ & $2.67 \pm .67^{\mathrm{a}}$ \\
\hline D & $1.67 \pm .88^{\mathrm{a}}$ & $2.00 \pm .58^{\mathrm{a}}$ \\
\hline E & $1.37 \pm .88^{\mathrm{a}}$ & $1.33 \pm .33^{\mathrm{a}}$ \\
\hline
\end{tabular}

Table 5: Monocyte Counts amongst Test Groups

Mean within the Same Column Followed by Different Suffixes Are Significantly Different $(\mathrm{P} \leq 0.05)$

A: uninfected

B: infected without treatment

C: infected and treated with clotrimazole

D: infected and treated with A. faecalis

E: prophylactic group

\begin{tabular}{|c|c|c|}
\hline Treatment Groups & Mean \pm S.E(initial) & Mean \pm S.E (final) \\
\hline $\mathbf{A}$ & $0.67 \pm .33^{a}$ & $0.67 \pm .67 \mathrm{a}$ \\
\hline B & $0.33 \pm .33^{a}$ & $0.00 \pm .00^{a}$ \\
\hline $\mathrm{C}$ & $0.66 \pm .66^{a}$ & $1.67 \pm .89^{a}$ \\
\hline $\mathrm{D}$ & $0.66 \pm .66^{a}$ & $0.33 \pm .33^{a}$ \\
\hline $\mathrm{E}$ & $1.00 \pm .58^{\mathrm{a}}$ & $0.67 \pm .33^{\mathrm{a}}$ \\
\hline
\end{tabular}

Table 6: Eosinophil Counts amongst Test Groups

Mean within the Same Column Followed by Different Suffixes Are Significantly Different ( $\mathrm{P} \leq 0.05)$ 
A: uninfected

B: infected without treatment

C: infected and treated with clotrimazole

D: infected and treated with A. faecalis

E: prophylactic group

\begin{tabular}{|c|c|c|}
\hline Treatment Groups & Mean \pm S.E(initial) & Mean \pm S.E (final) \\
\hline A & $0.33 \pm .33^{\mathrm{a}}$ & $0.33 \pm .33^{\mathrm{a}}$ \\
\hline B & $0.00 \pm .00^{\mathrm{a}}$ & $0.00 \pm .00^{\mathrm{a}}$ \\
\hline C & $0.00 \pm .00^{\mathrm{a}}$ & $0.67 \pm .33^{\mathrm{a}}$ \\
\hline D & $0.00 \pm .00^{\mathrm{a}}$ & $0.33 \pm .33^{\mathrm{a}}$ \\
\hline E & $0.33 \pm .33^{\mathrm{a}}$ & $0.00 \pm .00^{\mathrm{a}}$ \\
\hline
\end{tabular}

Table 7: Basophil Counts amongst Test Groups

Mean within the same column followed by different suffixes are significantly different $(\mathrm{P} \leq 0.05)$

A: uninfected

B: infected without treatment

C: infected and treated with clotrimazole

D: infected and treated with A. faecalis

E: prophylactic group

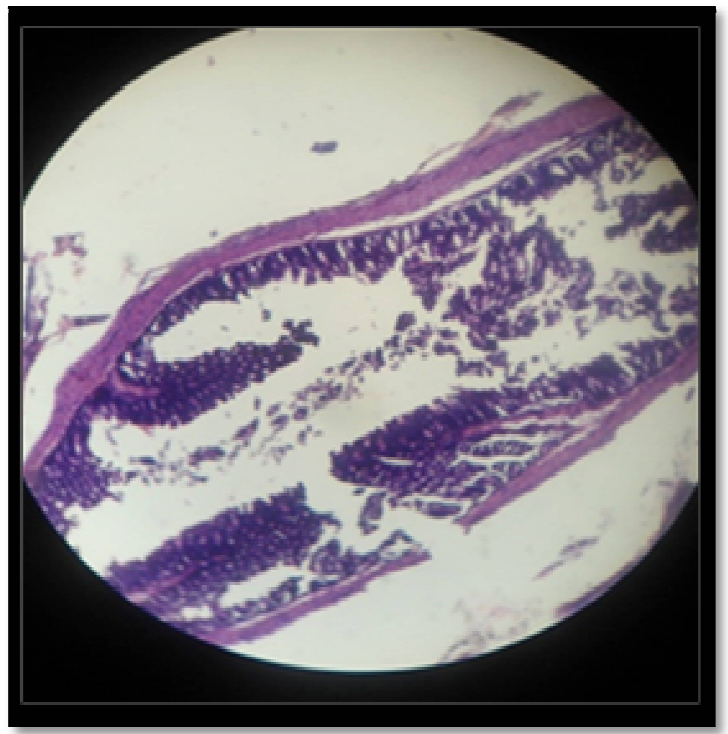

Figure 1: Vaginal Histology from Group A Showing Organised Vaginal Muscles

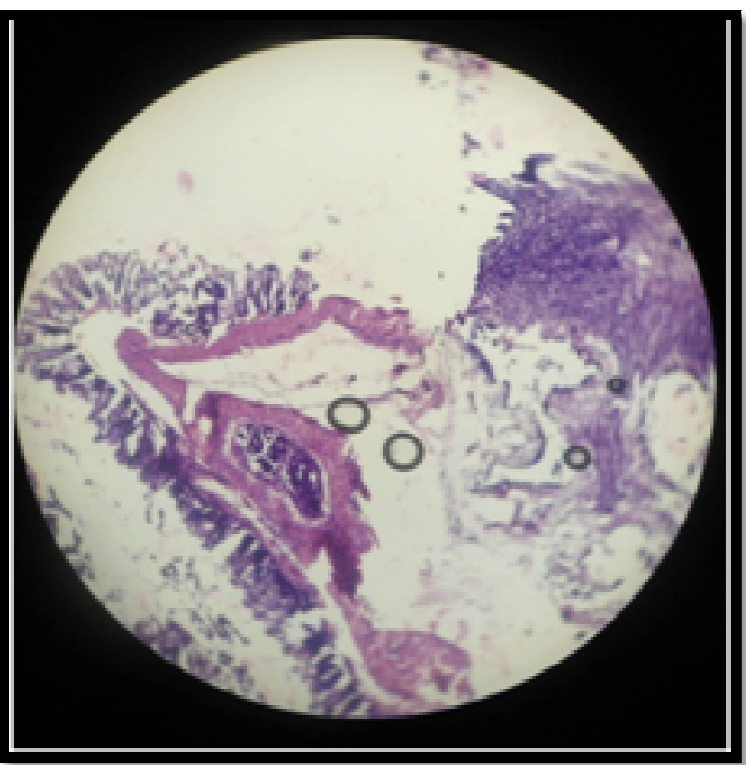

Figure 2: Vaginal Histology from Group B Showing Fibroblastic Disorganization of Vaginal Muscles 


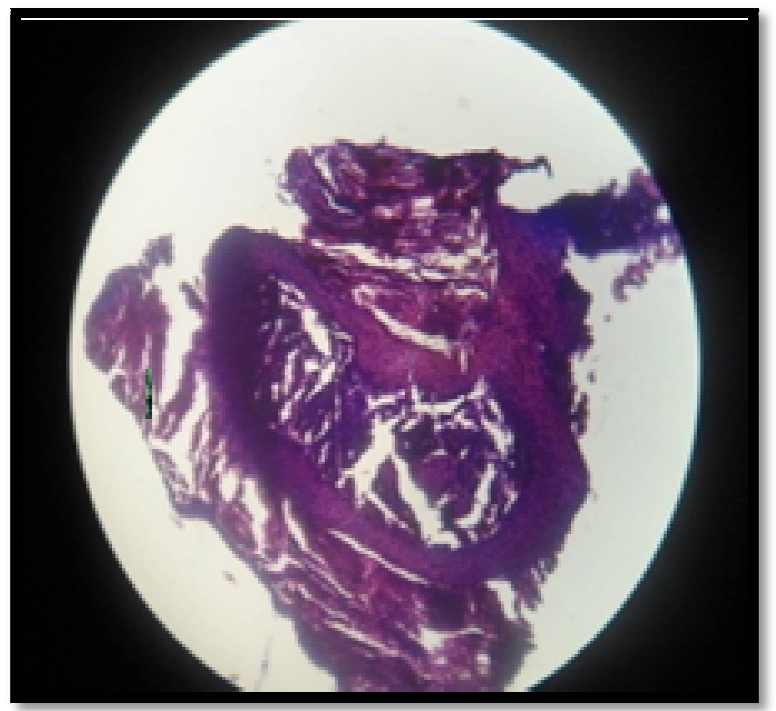

Figure 3: Vaginal Histology from Group C Showing Partially Recovered Vaginal Muscular Arrangement

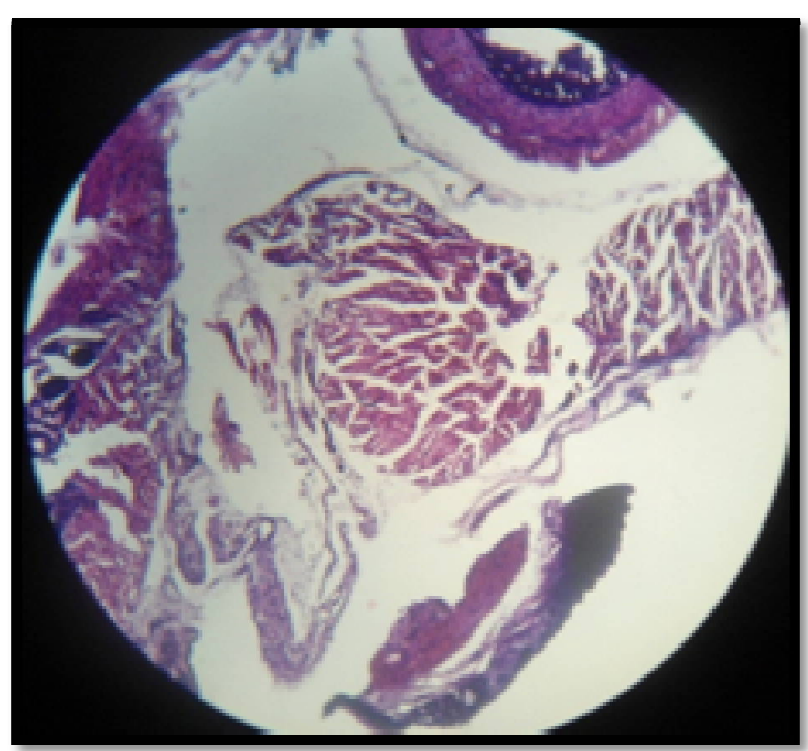

Figure 4: Vaginal Histology from Group D showing Recovered parts of the Vaginal Walls

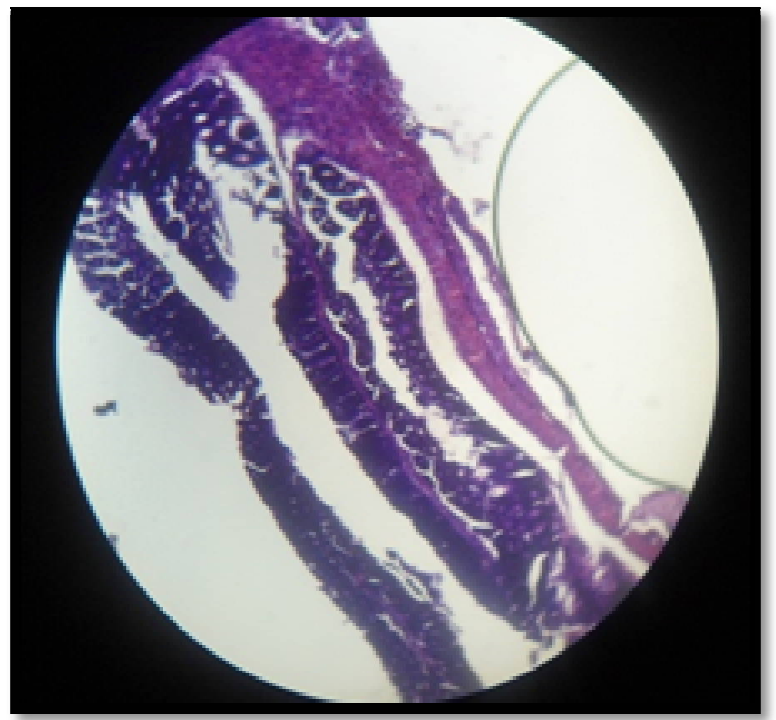

Figure 5: Vaginal Histology from Group E Showing Organized Vaginal Muscles 


\section{Discussion}

A.faecalis antifungal activities against C. albicans vaginal infection (Figure1) serves as a proof of the ability of the organism to possess antimicrobial activities which has been reported by Daraei et al. (2009). A. faecalis strain reported in their work had antifungal activities against C. albicans ATCC 10231 and Aspergillus niger. The immunomodulatory roles elicited by A. faecalis can be explained from the works of Jaafar et al. (2011) and Laroche \& Michaud (2007). They reported that the organisms cell wall contains variety of complex polysaccharide which have immunopotentiating and antitumorogenic effects. The immunomodulatory responses and antifungal activities synergistically aided the maintenance and repairs of the vaginal architecture of the test mice (Figure s 1-5).

\section{Conclusion}

Studies on the antifungal assessment of Alcaligenes faecalis in the prevention and control of vaginal candidiasis show that A. faecalis has antifungal activity against Candida albicansin vivo and also elicite immunomodulatory responses that aid in the control of vaginal candidiasis. This implies that A. faecalis has the potential to be harnessed for use as a natural alternative in the prevention of vaginal candidiasis. This could help to reduce the issue of microbial resistance to conventional antifungal agents.

\section{References}

i. $\quad$ Borchert, D., Sheridan, L., Papatsoris, A., Faruquz, Z., Barua, J.M., Junaid, I., Pati, Y., Chinegwundoh, F. and Buchholz,N. (2008). Prevention and Treatment of Urinary Tract Infection with Probiotics: Review and Research Perspective. Indian Journal of Urology.24(2): 139-144.

ii. Daraei, M. Gholamhossein, E. and Javad, F. (2009). Isolation of a Strain of Alcaligenes faecalis with Wide Range Antimicrobial Activity from Oil-polluted Soil. SIM Annual Meeting and Exhibition, Industrial Microbiology and Biotechnology.

iii. Gibson, G.R. and Fuller, R. (2000). Aspects of in Vitro and in Vivo Research Approaches Directed Towards Identifying Probiotics for Human Use. Journal of Nutrition. 130: 391-395.

iv. Jaafar, M.R., Jakob, S., Kania, W.P. and Buchmann, K. (2011). Dose Dependent Effects of Dietary Immunostimulants on Rainbow Trout Immune Parameters and Susceptibility to the Parasite Ichthyophthirius Multifiliis.Journal of Aquac culture and Resource Development 10:2155-9546.

v. Kahveci, A., Asicioglu, E., Tigen, E., Ari, E., Arikan, H., Odabasi, Z. and Ozener, C. (2011) Unusual Causes of Peritonitis in a Peritoneal Dialysis Patient: Alcaligenes faecalis and Pantoea agglomerans. Annals of Clinical Microbiology and Antimicrobials10: 12.

vi. Laroche, C. and Michaud, P. (2007).New Developments and Prospective Applications for $\beta$-(1,3)Glucans.Recent Patents

vii. on Biotechnology. 1: 59-73.

viii. Pascual, L., Ruiz, F., Giordano, W. and Barberis, L. (2009). Vaginal Colonization and Activity of the Probiotic Bacterium Lactobacillus fermentum $\mathrm{L}_{23}$ in a Murine Model of Vaginal Tract Infection. Journal of Medical Microbiology. 59 (3): 360-364.

ix. Phytopharma (2006). Probiotics in Poultry. www.somphyto.com/ probiotics, accessed on September 18, 2012.

x. Santos, S.N., Oliviera, L.K., Itamar, S.M., Velozo, S. and Milton, R. (2011). Antifungal Activity of Bacterial Strains from the Rhizosphere of Starchytarpheta crassifolia. African Journal of Biotechnology10 (25): 4996-5000. 